\title{
Possible Evolution of Paroxysmal Nocturnal Hemoglobinuria into Chronic Myeloid Leukemia: A Rare Transformation
}

\author{
Jinqiong Li' ${ }^{1}$ Mohammad Arphan Azaad ${ }^{2}$, Yongping Li $^{2 *}$ \\ ${ }^{1}$ Post Graduate Student Department of Clinical Medical College, Dali University, Dali, China \\ ${ }^{2}$ Department of Hematology, Affiliated hospital, Dali University, Dali, China \\ Email:173844678@qq.com, arphanazaad@hotmail.com, *yongping_li@hotmail.com
}

How to cite this paper: Li, J.Q., Azaad, M.A. and Li, Y.P. (2017) Possible Evolution of Paroxysmal Nocturnal Hemoglobinuria into Chronic Myeloid Leukemia: A Rare Transformation. Open Journal of Blood Diseases, 7, 29-35.

https://doi.org/10.4236/ojbd.2017.71003

Received: December 17, 2016

Accepted: January 6, 2017

Published: January 9, 2017

Copyright $\odot 2017$ by authors and Scientific Research Publishing Inc. This work is licensed under the Creative Commons Attribution International License (CC BY 4.0).

http://creativecommons.org/licenses/by/4.0/

\begin{abstract}
$\mathrm{PNH}$ is a rare acquired clonal hematopoietic stem cell disorder characterized by abnormal sensitivity of red blood cells to lysis by complement. It is caused by genetic mutation resulting in deficiency of glycosyl phosphatidylinositol anchor (GPA) for cell membrane proteins including complement regulating proteins CD55 and CD59. PNH tends to be associated with Aplastic Anemia (anemia due to failure of the bone marrow to produce red and white blood cells as well as platelets), Myelodysplastic Syndrome (a group of cancers in which immature blood cells in the bone marrow do not mature or become healthy blood cells) or rarely Acute Myeloid Leukemia (AML) (also known as acute nonlymphocytic leukemia, representing a group of clonal hematopoietic stem cell disorders in which both a block in differentiation and unchecked proliferation result in the accumulation of myeloblasts at the expense of normal hematopoietic precursors). Here we report a case and assume possible evolution of PNH into CML (a myeloproliferative malignant clonal disease characterized by presence of fusion BCR/ABL fusion oncogene).
\end{abstract}

\section{Keywords}

Paroxysmal Nocturnal Hemoglobinuria (PNH), Chronic Myeloid Leukemia (CML)

\section{Case Report}

A 52 years old male patient presented with complains of fatigue, tinnitus, exertion, and feeling of fullness of abdomen for 4-day duration. The patient was recently treated for chest infection with antibiotics. Past medical, surgical, and al- 
lergic history was insignificant. The patient is a smoker and alcoholic. On arrival the patient was vitally stable. He was icteric on examination. Chest and CVS examination were within normal limits. Per abdominal examination revealed splenomegaly. Complete blood count was sent which revealed excessive leukocytosis, low hemoglobin and $\mathrm{RBC}$ (details of $\mathrm{CBC}$ with $\mathrm{CBC}$ report on further admission are listed in Table 1). Liver function test was sent which revealed raised indirect bilirubin and total bilirubin (details of bilirubin profile with bilirubin profile on further admission are listed in Table 2). USG of Abdomen/Pelvis was done which revealed massive splenomegaly and mild hepatomegaly. Bone marrow (aspiration/biopsy) revealed CML with BCR/ABL positive. Serology test for hepatitis virus was non-reactive. LDH level was significantly elevated (1374 U/L). CD55 \& CD59 profile was in a lower range in initial investigation (details of CD55 \& 59 profile with further CD55 \& CD59 profile are listed in Table 3). JAK2V617F test was negative. Coagulation profile and urine routine examinations were within normal limits.

On the basis of above evidence the patient was admitted with diagnosis of chronic myeloid leukemia and PNH. Then he was treated with Hydroxyurea, folic acid, cobalamin and other supportive treatment. The combination of CML and PNH itself is a rarity so we would like to report this case.

\section{Discussion}

Paroxysmal nocturnal hemoglobinuria (PNH) is an acquired disorder of the hematopoietic stem cell that makes blood cells more sensitive to the action of complement. Patients experience intravascular hemolysis, smooth muscle dystonia,

Table 1. (a) Comparing complete blood count levels at admission and at future admission; (b) Comparing bilirubin profiles at admission and at future admission.

(a)

\begin{tabular}{cc}
\hline \multicolumn{1}{c}{ Date } & Complete Blood Count \\
\hline 2014-03-28 & WBC: $306.49 \times 10^{9} / \mathrm{L}, \mathrm{RBC}: 2.59 \times 10^{9} / \mathrm{L}, \mathrm{Hb}: 79 \mathrm{~g} / \mathrm{L}, \mathrm{MCV}: 91.9 \mathrm{fl}, \mathrm{PLT}: 293 \times 10^{9} / \mathrm{L}$ \\
$2014-05-09$ & WBC: $63.94 \times 10^{9} / \mathrm{L}, \mathrm{RBC}: 3.89 \times 10^{12} / \mathrm{L}, \mathrm{Hb}: 113 \mathrm{~g} / \mathrm{L}, \mathrm{MCV}: 92.8 \mathrm{fl}, \mathrm{PLT}: 405 \times 10^{9} / \mathrm{L}$ \\
$2014-08-15$ & WBC: $3.89 \times 10^{9} / \mathrm{L}, \mathrm{RBC}: 4.07 \times 10^{12} / \mathrm{L}, \mathrm{Hb}: 122 \mathrm{~g} / \mathrm{L}, \mathrm{MCV}: 88.9 \mathrm{fl}, \mathrm{PLT}: 405 \times 10^{9} / \mathrm{L}$ \\
\hline & $(\mathrm{b})$ \\
\hline Date & Bilirubin Profile \\
\hline $2014-03-28$ & TBI: $59.9 \mathrm{umol} / \mathrm{L}, \mathrm{DBI}: 7 \mathrm{umol} / \mathrm{L}, \mathrm{IBI}: 52.9 \mathrm{umol} / \mathrm{L}$ \\
$2014-05-09$ & TBI: $22.2 \mathrm{umol} / \mathrm{L}, \mathrm{DBI}: 6.5 \mathrm{umol} / \mathrm{L}, \mathrm{IBI}: 15.7 \mathrm{umol} / \mathrm{L}$ \\
$2014-08-15$ & TBI: $22.5 \mathrm{umol} / \mathrm{L}, \mathrm{DBI}: 10 \mathrm{umol} / \mathrm{L}, \mathrm{IBI}: 12.5 \mathrm{umol} / \mathrm{L}$ \\
\hline
\end{tabular}

Table 2. Comparing flow cytometric analysis of CD55 \& CD59 at admission with future admission.

\begin{tabular}{c}
\hline Comparing Flow Cytometric Analysis of CD55 \& CD59 \\
\hline $2014-04-01$ CD55 (RBC): $87.21 \%$, CD59 (RBC): $90.74 \%$ CD55 (WBC): $98.07 \%$, CD59 (WBC): $80.43 \%$ \\
$2014-05-09$ CD55 (RBC): 94.73\%, CD59 (RBC): 91.55\% CD55 (WBC): 92.3\%, CD59 (WBC): $87.92 \%$ \\
\hline
\end{tabular}


Table 3. Listing different phases of CML.

\begin{tabular}{|c|c|c|c|}
\hline \multirow{2}{*}{$\begin{array}{l}\text { Accelerated Phase } \\
\text { WHO }\end{array}$} & \multirow[b]{2}{*}{ ELN } & \multicolumn{2}{|c|}{ Blast Phase } \\
\hline & & WHO & ELN \\
\hline 1) Spleen Persistent or increasing splenomegaly unresponsive to treatment & l & l & l \\
\hline $\begin{array}{l}\text { 2) WBC Persistent or increasing WBC }\left(>10 \times 10^{9} / \mathrm{L}\right) \text { unresponsive to } \\
\text { treatment }\end{array}$ & l & l & l \\
\hline 3) Blast cells $10 \%$ to $19 \%$ & 15 to $29 \%$ & $6>20 \%$ & $>30 \%$ \\
\hline 4) Basophils $>20 \%$ & $>20 \%$ & l & l \\
\hline 5) Platelets Count $>1000 \times 10^{9} / 1$ uncontrolled by therapy $<100 \times 10^{9} / 1$ & I & l & l \\
\hline unrelated to therapy & yes & I & l \\
\hline 6) $\mathrm{CCA} / \mathrm{Ph}+$ Present & Present & I & l \\
\hline 7) Extramedullary/Involvement & l & \multicolumn{2}{|c|}{ PresentPresent } \\
\hline $\begin{array}{l}\text { The criteria of AP are different, reflecting the difficulty of making the diagnosis } \\
\text { criteria of BP differ only for the percent of blast cells. Only one of the listed cri } \\
\text { agnosis of AP or BP. CCA/Ph+ = clonal chromosome abnormalities in } \mathrm{Ph}+\text { cel } \\
\text { BM. Excluding liver and spleen, including lymph nodes, skin, CNS, bone, and } \\
\text { BP: blast phase; WHO: World Health Organization; ELN: European Leukemia }\end{array}$ & $\begin{array}{l}\text { of this trans } \\
\text { iteria is suffi } \\
\text { lls. In periph } \\
\text { lung. AP: ac } \\
\text { Net; BM: bor }\end{array}$ & $\begin{array}{l}\text { sitory phr } \\
\text { ficient for } \\
\text { heral bloc } \\
\text { acceleratec } \\
\text { ne marro }\end{array}$ & $\begin{array}{l}\text { ase. The } \\
\mathrm{r} \text { the di- } \\
\text { od or in } \\
\text { d phase; } \\
\text { ow [3]. }\end{array}$ \\
\hline
\end{tabular}

renal failure, arterial and pulmonary hypertension, recurrent infectious diseases and an increased risk of notably dreadful thrombotic complications. These hematopoietic stem cells have acquired a somatic mutation in an X-linked gene: the phosphatidylinositol glycan class A (PIG-A). This gene is required for the synthesis of the glycosyl phosphatidylinositol (GPI) anchor, which is necessary to attach some proteins to the cell membrane. The lack of synthesis of the GPI anchor leads to the under expression of a variety of proteins on the hematopoietic stem cell surface and on all cell lines that are generated by it. By this mechanism, a lack of two important complement regulatory proteins is observed on the cell surface: "decay-accelerating factor" (DAF), also called "CD55" and "Membrane inhibitor of reactive lysis" (MIRL), also called "CD59". Thus, red blood cells are more vulnerable to the action of complement. This leads to a complement-mediated intravascular hemolysis [1].

Action of complement on healthy subjects and on $\mathrm{PNH}$ patient is listed on Figure 1.

For diagnosis of PNH flow cytometry analysis of CD55 and CD59 are necessary. Increased levels of $\mathrm{LDH}$, reticulocyte, indirect bilirubin are highly suggestive of PNH. Presence of dark coloured urine that is manifested in Urine R/E as hemoglobinuria and decreased haptaglobin are considered highly suggestive of PNH. Traditional test such as Sucrose Lysis Test and Ham's Test are replaced these days. It is considered unique condition in a sense that its manifestations may include hemolytic anemia (due to acquired intracorpuscular defect), pancytopenia (due to marrow failure) and tendency to have venous thrombosis. Hemolysis occurs throughout the day but patients may present for passing red concentrated urine in the morning. As urine is more concentrated in the morning, this is when color is more pronounced. The hypothesis of increased hemolysis at night during sleep due to acidosis or low steroid levels is not supported by 


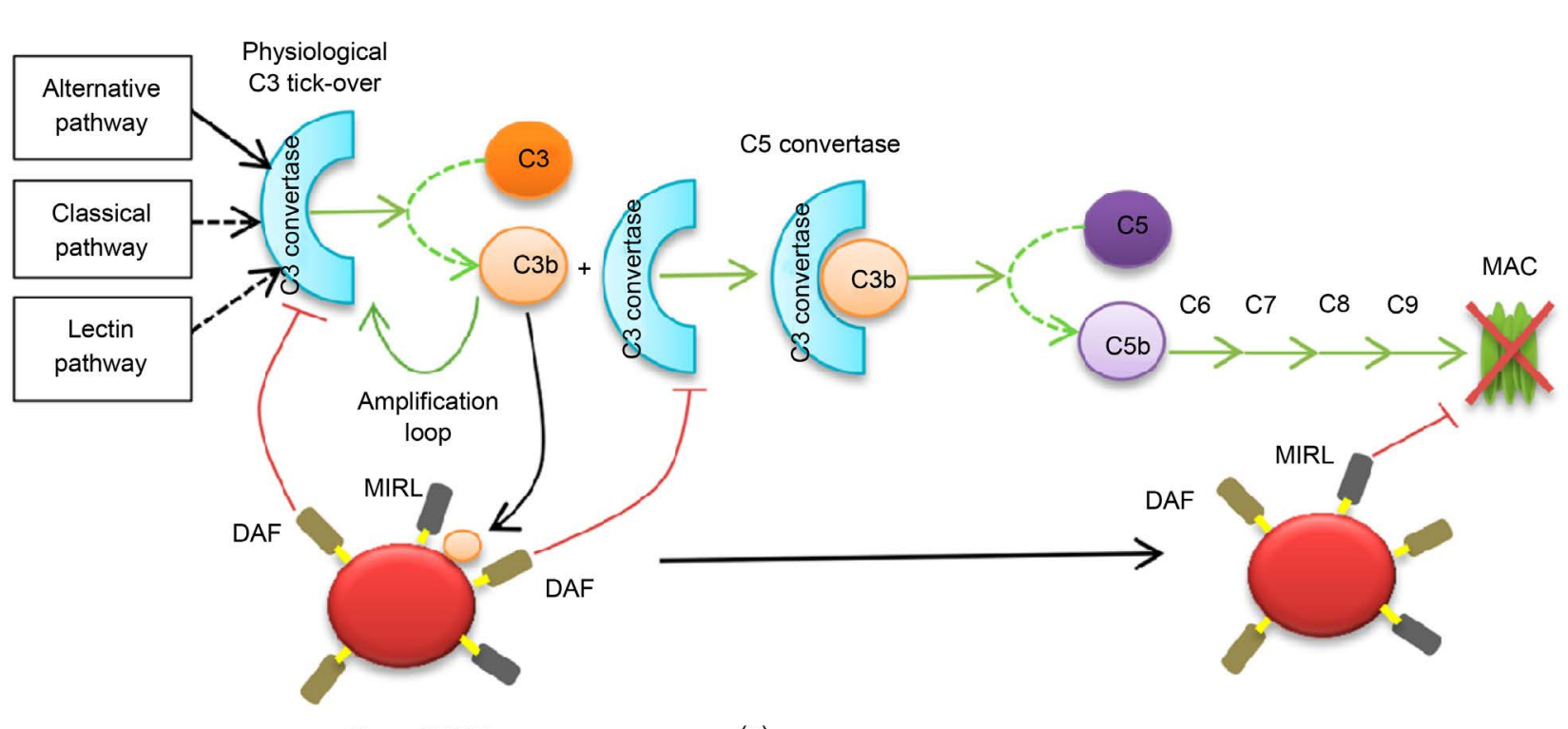

Normal RBC

(a)

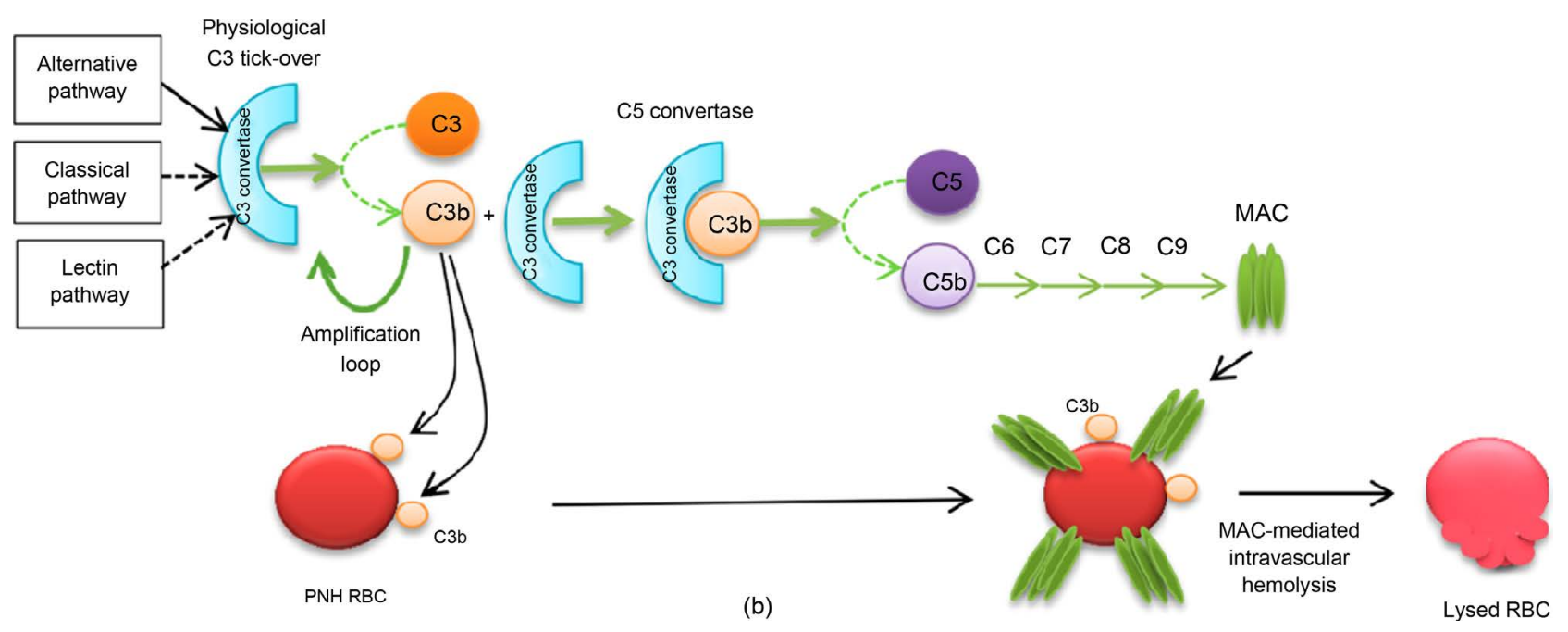

Figure 1. Action of complement in healthy subjects (a) and paroxysmal nocturnal hemoglobinuria (PNH) patients (b). (a) Due to the presence of membrane proteins MIRL and DAF, a normal RBC is protected from complement activation; (b) MIRL and DAF deficiency makes the RBC sensitive to complement attack, resulting in hemolysis. RBC, red blood cells, MAC, membrane attack complex, DAF, decay-accelerating factor [1].

studies. The gold standard diagnostic test for PNH is flow cytometer of RBCs to demonstrate absent or reduced expression of both CD55 and CD59. Patients with PNH experience a high incidence (14\% - 40\%) of thrombotic events, mostly venous and rarely arterial. Thrombotic events in PNH may occur despite thrombocytopenia or pancytopenia and they have a predilection for unusual locations in the venous system. The vessels mostly involved are visceral veins (hepatic, portal, mesenteric, splenic, and renal veins), followed by cerebral and dermal veins [2].

The Median age group of diagnosis of CML is 60 to 65 years. The translocation of the ABL gene from chromosome 9 to $22 \mathrm{t}(9 ; 22)(\mathrm{q} 3.4 ; \mathrm{q} 1.1)$ leads to the formation of a new, hybrid, fusion gene (BCR-ABL) that codes for an oncoprotein (P210, more rarely P190 or P230) that is located in the cytoplasm and has a 
strong, constitutively activated, tyrosine kinase activity, resulting in the activation of several downstream signals that transform hematopoietic stem cells. BCR-ABL-positive cells are genetically unstable and are prone to develop multiple and heterogenous genomic abnormalities, resulting in the transformation of the leukemic phenotype from chronic to acute, hence leading to the progression from chronic (CP) to accelerated and blast phases (AP, BP) [3]. Although symptoms at presentation may include lethargy, weight loss, unusual bleeding, sweats, anemia, and splenomegaly, in more developed countries, $50 \%$ of patients are asymptomatic and are diagnosed as a consequence of blood tests performed for unrelated reasons. More than $90 \%$ of CML patients are diagnosed when their disease is in a relatively early phase known as the chronic phase (CP). CML-CP is characterized by the presence of the Philadelphia $(\mathrm{Ph})$ chromosome and the oncogene that it encodes in the vast majority of myeloid cells and some lymphocytes. The $\mathrm{Ph}$ chromosome results from a $(9 ; 22)(\mathrm{q} 34 ; \mathrm{q} 11)$ reciprocal translocation that juxtaposes the $\mathrm{c}$-abl oncogene $1(A B L 1)$ gene on chromosome 9 with the breakpoint cluster region $(B C R)$ gene on chromosome 22, generating the $B C R-A B L 1$ fusion oncogene with greatly enhanced $A B L 1$ kinase activity. It is generally accepted that acquisition of the $B C R-A B L 1$ oncogene is the initiating event in the genesis of CML-CP, despite various lines of evidence suggesting that, at least in some cases, hematopoiesis may already be clonal before the acquisition of the $\mathrm{Ph}$ chromosome. It is believed that acquisition of the $B C R-A B L 1$ gene occurs initially in a single HSC that gains a proliferative advantage and/or aberrant differentiation capacity over its normal counterparts, giving rise to the expanded myeloid compartment [4].

Most of the CML at the time of diagnosis are at Chronic Phase. The treatment of CML was historically based on busulfan, that should no longer be used, then on hydroxyurea, that is still used for a short and quick pretreatment phase in case of marked leukocytosis or thrombocytosis. Interferon- $\alpha$ (IFN $\alpha$ ) became the gold standard in the $90 \mathrm{~s}$ and for a decade, before the introduction of tyrosine kinase inhibitors (TKI). Imatinib was the first TKI to be used and is still the gold standard of first-line treatment worldwide. More recently, the second-generation TKI nilotinib and dasatinib have been tested and approved for second-line, then also for first-line treatment [3].

The natural history of untreated CML is biphasic or triphasic: an initial indolent chronic phase (CP) is followed by an accelerated phase (AP), a blast phase (BP), or both [5].

On previous studies there has been association between $\mathrm{PNH}$ and AA, MDS and very few Acute Leukemia. The association of $\mathrm{PNH}$ with CML is indeed rare occurrence. This case we are reporting was diagnosed with $\mathrm{PNH}$ and CML at same time. So we assume that this patient must had PNH few years back, which was not diagnosed at that time and now $\mathrm{PNH}$ has transformed into CML.

$\mathrm{PNH}$ is a disease originating from a multipotent hematopoietic stem cell, caused by a somatic mutation in the X-linked PIG-A gene, which abrogates synthesis of the GPI-anchored proteins (GPI-AP), resulting in the deficiency of cell 
surface CD55 and CD59. Absence of CD55 and CD59 in particular explains the intravascular hemolysis, due to failure to inactivate the late components of complement. It was originally recognized as a hemolytic anemia, but bone marrow failure and developed to MDS and acute leukemia were also related to $\mathrm{PNH}$, demonstrating that $\mathrm{PNH}$ is a clonal disorder.

The coexistence of PNH and AA was first reported in 1944 by Dacie JV. PNH may arise de novo or in the setting of AA. In long-term survived severe AA patients, GPI anchor-deficient hematopoietic cell populations emerge at a high frequency (29\% to 52\%), suggesting a pathological link between these two disorders. Although many AA patients exhibit no signs of PNH when the PNH clone size is small, most, but not all, will experience further expansion of the PIG-A mutant clone and progress to classic PNH.

$\mathrm{PNH}$ clone has also been detected in MDS patients. By high-resolution flow cytometry, approximately $15 \%-20 \%$ of low-risk MDS patients have been found to have a detectable GPI-AP-deficient erythrocytes and leucocytes, but sequencing of the PIG-A gene to establish clonality has not been performed in many of these studies.

In most PNH transformed AML, the leukemic clone was derived from the PNH clone, genetic instability of PNH might be the underlying mechanism [6].

\section{Conclusion}

To our knowledge there has been only one reported case of PNH transformation into CML. This is indeed rare condition. The possible link between PNH and CML is poorly understood. Possible explanation may include the blasts of CML which were indeed originated from PNH clones. One of the other possible explanations may include $\mathrm{PNH}$ providing favorable environment for the development of CML.

\section{References}

[1] Devalet, B., Mullier, F., Chatelain, B., Dogné, J.M. and Chatelain, C. (2015) Pathophysiology, Diagnosis, and Treatment of Paroxysmal Nocturnal Hemoglobinuria: A Review. European Journal of Haematology, 95, 190-198. https://doi.org/10.1111/ejh.12543

[2] Memon, A.R., Khan, R., Rauf, M.U. and Shafique, K. (2014) Paroxysmal Nocturnal Hemoglobinuria Presenting as Cerebral Venous Sinus Thrombosis: A Case Report. International Archives of Medicine, 7, 39. https://doi.org/10.1186/1755-7682-7-39

[3] Baccarani, M., Pileri, S., Steegmann, J.L., Muller, M., Soverini, S. and Dreyling, M. (2012) Chronic Myeloid Leukemia: ESMO Clinical Practice Guidelines for Diagnosis, Treatment and Follow-Up. Annals of Oncology, 23, vii72-77. https://doi.org/10.1093/annonc/mds228

[4] Perrotti, D., Jamieson, C., Goldman, J. and Skorski, T. (2010) Chronic Myeloid Leukemia: Mechanisms of Blastic Transformation. Journal of Clinical Investigation, 120, 2254-2264. https://doi.org/10.1172/JCI41246

[5] Lewen, M., Gresh, R., Queenan, M., Paessler, M., Pillai, V., Hexner, E., Frank, D., Bagg, A., Aplenc, R., Caywood, E. and Wertheim, G. (2016) Pediatric Chronic Myeloid Leukemia with inv(3)(q21q26.2) and T Lymphoblastic Transformation: A 
Case Report. Biomarker Research, 4, 14. https://doi.org/10.1186/s40364-016-0069-0

[6] Chen, Y., Tao, S., Deng, Y., Song, L. and Yu, L. (2015) Chronic Myeloid Leukemia Transformation in a Patient with Paroxysmal Nocturnal Hemoglobinuria: A Rare Case Report with Literature Review. International Journal of Clinical and Experimental Medicine, 8, 8226-8229.

Submit or recommend next manuscript to SCIRP and we will provide best service for you:

Accepting pre-submission inquiries through Email, Facebook, LinkedIn, Twitter, etc. A wide selection of journals (inclusive of 9 subjects, more than 200 journals)

Providing 24-hour high-quality service

User-friendly online submission system

Fair and swift peer-review system

Efficient typesetting and proofreading procedure

Display of the result of downloads and visits, as well as the number of cited articles Maximum dissemination of your research work

Submit your manuscript at: http://papersubmission.scirp.org/

Or contact ojbd@scirp.org 